\title{
Marguerite Duras, Lol V. Stein: escrita \\ e tradução em andamento
}

\author{
Marguerite Duras, Lol V. Stein: writing \\ and translation in tempo
}

Viviane Veras ${ }^{\star}$

\section{RESUMO}

O saber-fazer do tradutor, do ponto de vista ético, poderia ser visto como soma de saberes acumulados em sua experiência de traduzir. Talvez não baste. Talvez seja preciso contar com o estranhamento que o texto põe em cena, e que solicite uma tradução que se ponha à escuta do que nessa escrita perturba e dá lugar ao equívoco, e que busque uma sintonia que dê voz ao que resiste, mas que também ceda à partilha de seus silêncios. Esse saber-fazer exige um manejo do tempo e uma disposição ao imprevisto, ao improviso e, quem sabe, a um ato de criação.

Palavras-chave: tradução; escuta; tempo.

\section{ABSTRACT}

From an ethical point of view, expertise in translation could be seen as the sum of all accumulated knowledge in one's experience as a translator. Yet this might not suffice. Perhaps the translator needs to rely on the uncanny place one inhabits when translating a text. In this sense, translation demands that one listen to that which disturbs in writing and gives way to equivocation. Translation turns out to require an attunement to spaces of resistance in the text, an act that also yields possibilities of partaking in what remains silent. Expertise thus requires special ways of grappling with time and of being open to the unexpected, to the contingent, and perhaps to an act of creation.

Keywords: translation; listening; time.

\footnotetext{
* Universidade Estadual de Campinas (Unicamp)
} 
Veras, M. V.

Marguerite Duras,

Lol V. Stein:

escrita e tradução

em andamento

Escrever. Não posso. Ninguém pode.

É preciso dizer: não se pode. E se escreve.

É o desconhecido que trazemos conosco: escrever, é isto o que se alcança. Isto ou nada.

Marguerite Duras ${ }^{1}$

Escrever somente começa quando escrever é abordar aquele ponto em que nada se revela... Ninguém escreve se não produzir a linguagem apropriada para manter ou suscitar o contato com esse ponto.

Maurice Blanchot ${ }^{2}$

Revista Letras,

1 DURAS (1994,p. 47). Essa e todas as traduções não referenciadas são de minha responsabilidade.

2 BLANCHOT (1987, p. 42).

Curitiba, UfPR, n. 95 60-72,

jan./jun. 2017.

ISSN 2236-0999

(versão eletrônica) 

a sei de onde me veio o leixa-pren das cantigas medievais. É provável que tenha restado dos seminários de Jacques Lacan sobre o que o atraía no trovar, no trouver. Quem sabe por ter escutado em sua Homenagem a Marguerite Duras ([1965]2003) o galanteio de um Lacan trovador. Quem sabe por ter me deixado entrar no jogo da perturbadora voz narrativa da história sem história de Lol V. Stein. Ou, ainda, por estar atenta ao enigma do título - Le ravissement de Lol V. Stein - que faz ressoar na homenagem lacaniana a operação de tradução a que se entrega Freud, quando pensa outras línguas como desvios para retornar à palavra alemã unheimlich e constatar que a definição que buscava permanece incompleta: "sempre algo que não se sabe como abordar" ([1919]1996, p. 239) ou "sempre algo em que nos achamos desarvorados, por assim dizer" ([1919]2010, p. 250). A palavra se traduz em português por estranho, inquietante, inquietante estranheza, estranheza inquietante, estranho familiar, infamiliar... passando ou não pelas traduções inglesa ou francesas. E é precisamente porque algo desse intraduzível se desloca por essa multiplicidade de traduções que "em sua pervivência [Fortleben]... o original se modifica” (BENJAMIN, 2010, p. 211) - o que leva Freud a reconhecer que também nele, em seu unheimlich, não há estabilidade; que revelado pela tradução o original vacila.

Certamente, ao menos nesse momento, não é a curiosidade freudiana por uma estética que considere além do belo e do sublime aquilo que causa 
Veras, M. V. Marguerite Duras, Lol V. Stein: escrita e tradução em andamento
Revista Letras,

Curitiba, UFPR, n. 95 60-72, jan./jun. 2017. ISSN 2236-0999 (versão eletrônica) repulsa e aflição, nem a dispersão dessa estranheza por outras línguas que move Lacan em sua homenagem a M. Duras. É verdade. Mas é Freud quem vem lembrá-lo de que "em sua matéria, o artista sempre o precede" (2003, p. 200). Lacan reconhece na criação de Marguerite um saber sobre a psicanálise, sobre o feminino, sobre a loucura, em "uma prática da letra que converge com o uso do inconsciente" (p. 200). No que ela escreve sobre Lol V. Stein revela-se o que ele ensina; revela-se um saber que o desafia, que o arrebata, que o leva (quem sabe, de certa forma, como Freud e a Gradiva de Jensen, e Saussure e os anagramas de Pascoli ${ }^{3}$ ) a procurar saber diretamente dela, ouvir da boca de Marguerite esse segredo. Mas M. Duras responde que não sabe de onde lhe viera esse nome, essa Lol V. Stein. Diz mesmo que não tinha como saber. E escreve depois, falando de Lacan e dirigindo-se também a ele: "ninguém pode conhecê-la, nem você nem eu" (1994, p. 23).

Resta a obra. Só ela confirma esse poder oracular da arte que marcou a teorização e a prática da psicanálise em Freud e em Lacan. A homenagem, portanto, é também uma homenagem à literatura. $\mathrm{O}$ ravissement é traduzido e declinado em uma dança de palavras que reafirmam a ambivalência inscrita na etimologia - entre o êxtase, o rapto, a rapina, a devastação - e a mensagem cifrada $^{4}$ na escrita de Marguerite. Afinal, quem arrebata? Quem é arrebatado? Quem se deixa-prender nesse jogo de amor(te)?

Há como ler essa escrita de M. Duras sem esse deixar-se-prender? Posso responder, sem precipitação, que há formas de se deixar prender. Apesar de ter lido antes o pequeno texto de Lacan numa publicação portuguesa de 1989, traduzida como Homenagem a Marguerite Duras pelo arrebatamento de Lol V. Stein, não estranhei o título da tradução brasileira do romance (afinal, Marguerite também deslumbra, seduz Lacan), e tinha-o comigo também em francês. O que me prendia nessa primeira leitura ${ }^{5}$, na segunda metade dos anos 1990, era uma aventura literária marcada pela loucura da personagem. Movida pela homenagem lacaniana, procurava no romance o "ser a três" arranjado por Lol, e que se desfazia

3 Segundo Giuseppe Nava, "Saussure havia escrito a Pascoli, provavelmente no final de 1908, para perguntar-lhe se havia empregado de modo consciente o método da composição anagramática em seus Carmina; foi justamente o silêncio de Pascoli - interpretado como um sinal de desacordo em relação à pesquisa - que teria levado Saussure a abandonar seus estudos sobre essa questão" (NAVA, 1968, p. 73).

4 Lacan fala da dança dos personagens como um nó que se reata, um nó a três que inclui o narrador (já se distanciando da Carta roubada, escrita em 1956). A topologia dos nós, contudo, só vai ser apresentada como uma escrita na década de 1970, exigida então pelo trabalho de leitura do Finnegans Wake de James Joyce.

5 A primeira leitura foi a da tradução brasileira de 1986, com o título O deslumbramento (cito-a neste texto). Escolho, contudo, o arrebatamento da edição portuguesa de uma seleção de textos de Jacques Lacan (1989) traduzida por José Martinho (essa é também a opção da tradução brasileira de Vera Ribeiro para o texto homenagem de Lacan a Duras publicado em Outros Escritos, 2003). Não se sabe se o título em português brasileiro foi uma escolha editorial, trazendo sob ele, em letras menores e entre parênteses, o título francês (Le ravissement de Lol V. Stein). Talvez para que o livro pudesse fazer série com $O$ amante e $A$ dor, obras de Marguerite Duras já publicadas pela editora e anunciadas na capa sob essa equação bilíngue. É importante sublinhar que o nome da tradutora, Ana Maria Falcão, também aparece à margem da capa, o que não é usual. 
logo nas primeiras páginas, no baile do Casino de T. Beach, quando a jovem tem seu noivo arrebatado por Anne-Marie Stretter; uma trama de olhares entre personagens e narrador nos ternários que se repetiam. Contentava-me, assim, com essa forma de fazer sentido, e esse era um modo de ler, entendo hoje, bem pouco, se assim posso dizer, lacaniano. Querendo compreendê-lo.

A leitura de $\grave{A}$ l'écoute de Jean-Luc Nancy (2002) reacendeu uma cisma que já me acompanhava há algum tempo com relação ao mito ovidiano tal como trabalhado em Freud e pelo menos até os últimos seminários de Lacan - um narcisismo sem eco, a voz petrificada, Stein. De início, Nancy fala da filosofia, das formas como a evidência, o olhar e a visão neutralizam a escuta. Mas pouco depois afirma que há escuta em todo discurso, e que talvez seja necessário "não se contentar com fazer sentido (com ser logos), mas que além disso ressoe" (2002, p. 19). Foi o que em leituras mais recentes busquei na escrita e na tradução, relendo e retraduzindo buscando não só a compreensão e a legibilidade pela via do significado, mas também a ressonância do original atravessando sua tradução, atenta aos descompassos entre o que se mostra e o que se enuncia, aos gritos, às palavras-buraco que se escrevem sem nomear. "São os brancos que se impõem diz Marguerite em conversa com Xavière Gauthier - Isso se passa assim: digo a você como isso se passa; são os brancos que aparecem, talvez sob o golpe de uma rejeição violenta da sintaxe, sim, reconheço alguma coisa aí” (1974, p.12). Sob o signo da traição redimida pelo apelo à fidelidade, a tradução parece não suportar bem essa marcação vazia, a falta de travessões, aspas, pontuação, e põe em cena um dêitico que oriente o leitor, um verbo que faça fluir a frase nominal, um elemento coesivo que permita ligar o rarefeito, uma vírgula que elimine a ambiguidade - Anne-Marie Stretter fora ignorada ou os outros haviam ignorado o que ela conhecera? Qu'avait-elle connu, elle que les autres avaient ignoré? (p. 16) O que havia conhecido, ela, que os outros tinham ignorado?o (p. 10)

Foi a descoberta desse sujeito corpo-escuta nomeado por Nancy “diapasão sujeito”, cada um diferentemente regulado (p. 37), que me levou a ler - dessa vez e de muitas outras, porque reli a tradução, cotejando e cortejando - me pondo à escuta do ravissement, seguindo os passos que dançam e perambulam do começo ao fim do livro, sendo levada - mesmo que agora afirma que me deixei levar pelo tempo ritmado pelas andanças errantes de Lol V. Stein pelas alamedas e parques de S. Tahla; pelo tempo não dissociado dos espaços percorridos; pelo tempo marcado nas vozes e nos olhares, entre o grito, a boca aberta que diz nada e a pupila descolorida do não-olhar; pela interrupção que, diz Blanchot, "aqui não é necessária nem simplesmente marcada por silêncio, branco ou vazio (...), mas por uma mudança na forma ou na estrutura da linguagem (2010, p.134)

Escuto o leixa-pren. Aposto no acaso dessa escuta. No que Nancy, escapando à fascinação da perspectiva, quase nomeou "ponto de escuta". Agora segundo a lógica da evocação, que convoca e invoca, "que antecipa sua vinda e

6 Todas as citações de Le ravissement... (1964) e de O deslumbramento (1986) estão em itálicos. 
Veras, M. V. Marguerite Duras, Lol V. Stein: escrita e tradução em andamento
Revista Letras,

Curitiba, UFPR, n. 95 60-72, jan./jun. 2017. ISSN 2236-0999 (versão eletrônica) retém sua partida”, suspensa entre dois tempos (2002, p. 42). É nessa suspensão que a narrativa do arrebatamento cria uma atmosfera musical, como timbre, fraseado, intensidade, aceleração, retardamento, repetição.

Lol V. Stein nasceu aqui, em S. Tahla, onde viveu uma grande parte de sua juventude. O pai era professor na Universidade. Ela tem um irmão nove anos mais velho - nunca o vi - dizem que mora em Paris. Os pais já morreram (1986, p. 7).

Contrariando esse início do romance que parece compartilhar uma história que conhece ou mimetiza, a voz narrativa tem sua fala pontuada por hesitações, lacunas, indeterminações, marcas de um não saber do que se conta: não sei, dizem... on dit que ... nunca ouvi dizer. O narrador não se nomeia, não há datas, o único nome próprio apresentado é o de Lol V. Stein. Mas o lugar ao leitor se oferece, talvez como o terceiro, ocupando seu lugar no relato - momento oportuno para esse arrebatamento, ou para simplesmente abandonar o livro.

O narrador não sabe. Nem Tatiana Karl, que logo se encaixa nesse relato como uma espécie de confidente, a melhor amiga de Lol. A mudança do tempo verbal marca o discurso indireto, no qual ressoa outro discurso: elas dançavam no pátio vazio, não queriam ficar na fila com as outras alunas, preferiam não sair do colégio, diz Tatiana. Nessa cena, um rádio toca: On danse, Tatiana? ...allez, Tatiana, allez viens, on danse, Tatiana, vien (1964, p. 11). Ouve-se pela primeira vez a voz de Lol na voz de Tatiana e no relato d'Ele. Ele é Jacques Hold, mas disso só se tem conhecimento quase na metade do livro.

A voz narrativa termina essa cena de música e dança adolescentes com um corte: É o que sei. Para. E inicia a segunda página, o parágrafo seguinte, com um Isto também: E conta, presto, que Lol havia conhecido Michael Richardson durante uma partida de tênis, ficaria noiva daí a seis meses, o casamento marcado para o outono, ela estava de férias por ocasião do grande baile no Casino Municipal de T. Beach. O que terá acontecido nesse baile? A voz se interrompe. É Tatiana quem volta a falar na narrativa.

Tatiana não acredita no papel preponderante desse famoso baile na doença de Lol. Tatiana busca as origens dessa doença em tempos mais remotos, bem antes da amizade delas (1986, p. 8, modifico a tradução, e volto a falar dela mais adiante ${ }^{8}$ ). Lol parecia perder a memória de vez em quando. No colégio já lhe faltava algo...

7 Há diversas pesquisas que contam o que se repete nesse livro de Marguerite Duras, e impressiona, apesar de muito comum na língua francesa escrita como marca de impessoalidade, o uso insistente do 'on', a repetição do 'elle', do advérbio 'lá. A tradutora alterna o on com a terceira pessoa do plural: on dit, disseram, contaram, ou como fórmula convencional de convite: Vamos dançar, Tatiana? O pronome elle alterna-se na tradução - ela - com o nome próprio Lol. Um problema que se pode apontar nesse caso é que o nome dessa personagem sofre mudanças em pontos ligados a mudanças na vida dela. Pronunciava seu nome com raiva: Lol V. Stein - era assim que ela se designava (p. 16).

8 A tradutora já havia acrescentado antes, na cena do pátio do colégio, uma marca de passagem do tempo que não aparece no texto em francês $-E$ depois disso. Agora, começa o parágrafo acrescentando uma preposição: Segundo Tatiana... Essas marcas temporais, alguns complementos e acréscimos explicativos conferem, é verdade, certa fluidez ao texto em português, mas algo do ritmo se perde. Alguns pontos chamam a atenção, particularmente no início, com a mistura de vozes narrativas, mas as escolhas tradutórias são, em geral, bem-sucedidas. 
não parecia sofrer, nunca estava exatamente ali, sempre de passagem. Lol V. Stein qui n'était par lá... son couer neétait pas - elle dit: lá... elle êut été toujours en allée (p. 13) ...Lol V. Stein não estava presente... seu coração não estava - ela diz: presente... ela estava sempre desligada... (p. 8). As paráfrases e apelos a sinônimos que evitam as repetições e introduzem referências mais precisas interferem na sonoridade, no ritmo, na musicalidade do parágrafo - em 11 linhas escutamos esse s'en aller (partir, desaparecer, evadir-se), que vai ressoando em allait, fiançailles, pareille, nouvelle, que se modulam ainda entremeadas pelas repetições elle, elle, elle... E a questão é que essas aliterações (além de outras) não poderiam ser subtraídas na tradução, uma vez que fazem parte da música das palavras, da gramática e da estilística da língua de M. Duras.

Tatiana não havia acreditado na paixão de Lol por Michael Richardson esse noivo seria apenas une fin de son cour inachevé 9 . A voz narrativa, em primeira pessoa, aparece agora destacada (p. 9) por espaços em branco, em uma espécie de monólogo exterior teatral, uma parábase, chamando a atenção do leitor para sua insegurança - do narrador? Do leitor? A quem se dirigem as vozes?

Não acredito em mais nada do que diz Tatiana, não estou convencido de nada.

Em seguida, volta à sua forma de construir, de inventar na história as partes que faltam.

Eis aqui, mescladas, do começo ao fim, ao mesmo tempo, essa falsa aparência que Tatiana conta e outra que invento sobre a noite do Casino de T. Beach. A partir dai contarei minha história de Lol V. Stein (p. 9, tradução modificada ${ }^{10}$ ).

Deixo suspenso esse incipit e faço uma digressão para falar dessas vozes agenciadas pelo narrador e nem sempre "vigiadas" por ele (que parece não saber o que dirão). Essas vozes em contraponto, embora possam desconcertar, não nos levam a recusar o pacto romântico e a tomar pelo avesso a suspensão voluntária da descrença. Mas, desconcertam. E não se reconhece nessa temporalidade ambivalente uma temporalidade propriamente narrativa.

Kundera (1986, p. 92) distingue essa polifonia da polifonia musical, afirmando que em literatura a simultaneidade de vozes é impossível. Faz em seguida uma ressalva e uma restrição: a não ser que o romance escape "à unilinearidade que lhe é própria por digressões ou por relatos encaixados, mas tal procedimento obriga a história que conta a se consagrar a um tema”. Não se pode dizer que a narrativa do arrebatamento é linear - do meio para o final do livro o narrador se limita a indicações cênicas: Acho isto: Vejo isto: Invento e vejo isto: Invento isto:... e pode-se pensar no episódio do baile, que retorna diversas vezes nos momentos talvez mais inesperados, como um tema; talvez como um ritornello, marcando os tempos. Contudo, a sugestão de que os capítulos e

9 No caso de o noivo ser apenas une fin de son cour inachevé (p. 13), um fim, um término, um complemento... a opção foi uma situação estável para seu coração inacabado (p. 9).

$10 \mathrm{Na}$ tradução brasileira há, depois de: Eis aqui, mescladas, do começo ao fim, ao mesmo tempo - o acréscimo de -, duas versões (para distinguir a versão de Tatiana e a outra, esclarecendo o leitor). 
Veras, M. V. Marguerite Duras, Lol V. Stein: escrita e tradução em andamento

Revista Letras,

Curitiba, UFPR, n. 95 60-72, jan./jun. 2017. ISSN 2236-0999 (versão eletrônica) partes das obras sejam separadas "de modo claro para o leitor" não permite que se considere na proposta de Kundera essa textura polifônica.

Talvez se possa pensar nessa polifonia a partir da escrita musical. Mas uma escrita também em pautas cujas linhas se entrelaçam. O físico Geza Szamosi (1986) descobre na teoria e prática da música polifônica e em sua notação ${ }^{11}$ um conceito de tempo único, desvinculado do movimento. Já havia a notação de vozes cantando diferentes melodias com base em uma única unidade temporal (o cantus firmus, ou o que Kundera chamaria de tema). Esses musicólogos conseguiram mais. Conseguiram comparar diferentes intervalos em várias melodias, e dividindo-os em partes desiguais ${ }^{12}$. A música se desdobra no tempo, como a escrita. E é nas linhas da escrita que o elemento musical se incorpora, intercalado aos silêncios. Transportando essas mudanças nas notações musicais para o andamento da narrativa de Marguerite Duras, pode-se, sem muito esforço, escutar as diversas vozes encaixadas ressoando em contrapontos na voz narrativa: a de Tatiana, a da mãe de Lol, a de Jean Bedford - o marido, a da governanta, a do porteiro do baile, e a de Jacques Hold, falando em terceira pessoa como narrador e em primeira como personagem. A música libera o tempo das amarras do movimento e dos calendários e cronômetros. A literatura libera-se do tempo linear e limitado, e há tempos já nos habituamos à perda da narratividade cronológica, a descontinuidades, fragmentações e a jogos metaficcionais que expõem os bastidores da ficção. Nas línguas de M. Duras se leem os sintagmas que se estranham, a sonoridade que exige mudanças de escalas, palavras que se desenlaçam, vozes que passeiam livres de marcações e, em especial, os tempos verbais que se misturam. Tomar o que nesses tempos se estranha na chave da compreensão é ler e traduzir o Ravissement como algo que se passou, deixando de lado o que há de singular na temporalidade kairológica dessa escrita.

Narrada com base ora em crenças, ora no ouvir dizer, ora em invenções, Jacques Hold ainda se pergunta: Quem, afinal, é Lol? Que existência pode ter, se feita em palavras que não a materializam? Lol V. Stein é uma criação do narrador? A partir daí contarei minha história de Lol V. Stein, afirma. Mas declara, duas páginas depois, que o fato de não poder captar o não-olhar de Anne-Marie Stretter, de não conseguir ver se ela havia olhado Michael Richardson de passagem, torna impossivel, portanto, saber quando começa minha história de Lol $\mathrm{V}$. Stein (p.11).

Quem fala agora? Certamente - agora não há mais dúvidas - alguém que se declara interessado na história de Lol. Seu gênero, ele, já se havia revelado na sutileza das concordâncias exigidas tanto pelo francês quanto pelo português. Trata-se dele. E ele não quer saber da adolescência, ou de qualquer outra coisa

11 O autor fala do século 12, da escola de música associada à Catedral de Notre Dame, em Paris (1986, p. 39)

12 Embora esses padrões sejam hoje considerados primitivos, foi um passo histórico, segundo Szamosi, porque conseguiram medir o tempo independente do movimento e do ambiente sem filosofia nem ciência, os músicos sabiam, sem Galileu, aquilo a que ele só precisou dar voz. 
dessa história que possa atenuar a esmagadora atualidade dessa mulher em minha vida (p. 9). Só vamos saber seu nome bem depois, caminhando para a metade do romance. E essa mulher, ele quer capturá-la em pleno movimento, vindo a seu encontro no baile. A orquestra para. A pista está vazia. A narrativa segue agora os passos de Anne-Marie Stretter (a mulher que vai roubar o noivo de Lol, bastando para isso ter entrado nesse momento no salão de baile). E dela conhecemos cada detalhe. Elegante. Alta. Magra. Mais velha. Vestido negro sob o qual se adivinhava o corpo. Graça de passáro morto que inquietava, conta Tatiana. Quem era? Soube-se mais tarde (p. 10).

Nessa encenação também a leitora se torna mais um ponto de escuta entre tempos: entre a chegada da aurora, fim da longa noite do baile - no exato momento em que Lol V. Stein tenta ainda seguir Michael e Anne-Marie (que passam por ela como se não a vissem), sua mãe entra esbravejando no salão e a filha sem o noivo grita alucinada e desmaia - e algumas semanas depois, ao anoitecer - quando Lol decide sair da casa dos pais, encontra Jean Bedford, um violinista que passava na rua (e suspeitava-se que tivesse estranhas inclinações por moças abandonadas, por moças que tivessem ficado loucas. p. 21), e casa-se com ele.

Passada a cena do baile, durante o qual Lol V. Stein permanece quase o tempo todo atrás das plantas verdes do bar (frase que também se repete várias vezes), o andamento muda. O tempo é acelerado. Passados 10 anos, com três filhas, Lola Valerie Stein volta para a casa dos pais (mortos) em S. Tahla. Uma casa em que reina a ordem, sempre no mesmo ritmo horário, sempre no verão. $\mathrm{O}$ narrador precisa agora inventar os elos que faltam nessa história. A governanta lembra um pouco. Ele mesmo acredita que lembra alguma coisa... Dele não se sabe ainda sequer o nome. Nem quando se torna, sabe-se só depois, o homem espreitado por Lol, escondida atrás de uma cerca viva, vendo-o beijar ardentemente outra mulher. Dessa mulher, Lol parece lembrar-se. Escondida, escuta, apesar do silêncio da noite, apenas suas palavras isoladas:

$$
\begin{aligned}
& \text { - Morte peut-être (1964, p. 38). } \\
& \text { - Morta talvez (traduzo) }{ }^{13} \text {. }
\end{aligned}
$$

Depois desse acontecimento Lol inventa de sair pelas ruas. Não chama a atenção dos moradores locais. Sua marca é ser a personagem Lola Stein, abandonada pelo noivo no Baile do Casino em T. Beach. Julga-se imersa em uma identidade de natureza indecisa que se poderia chamar de nomes indefinidamente diferentes (p. 30) ${ }^{14}$. Em entrevista a Michelle Porte, Marguerite fala de sua criatura: ela "é qualquer um que cada dia se lembra de tudo pela primeira vez, como se

13 O arranjo da frase na tradução que sigo - Talvez tenha morrido (p. 28) tira as palavras do isolamento que as faz ressoar como entreouvidas por Lol.

14 Também na passagem em que Lol caminha errante pelas ruas, a tradução substitui o "on" por pesssoas e habitantes que passam por Lol em suas andanças. Elle est là [... em] S. Tahla (p. 43) não pode ressoar na tradução de "là", que o processo de tradução transformou em Ela está presente (p. 31). 
Veras, M. V. Marguerite Duras, Lol V. Stein: escrita e tradução em andamento
Revista Letras,

Curitiba, UFPR, n. 95 60-72, jan./jun. 2017. ISSN 2236-0999 (versão eletrônica) houvesse entre os dias de Lol V. Stein abismos insondáveis de esquecimento. Ela não se habitua à memória. Nem ao esquecimento, aliás. Mas ela está ainda muito, muito encravada na escrita" (1977, p. 99).

Ele a segue pelas ruas da cidade. A cidade, Lol conhece de cor, e à medida que começa a reconhecê-la menos e menos o impacto da noite do baile parece ganhar mais e mais força. Não há palavra, apenas o inominável. Na falta dessa palavra, uma palavra-ausência, palavra-buraco... não se poderia dizê-la, mas se poderia fazê-la ressoar (p. 35, tradução modificada), um gongo vazio. A repetição do passado projetada nesse futuro sem futuridade faz que esse estranho retorno pareça estar vindo do futuro. O baile, navio de luz, está agora encalhado, e ela o protege, esse instante de fim de mundo, do qual só resta ela, per-sonne.

Lol reconhece nele o homem que vira por trás da cerca-viva beijando Tatiana Karl. A partir desse momento, sabe, ao menos isso, que ela vê nele $o$ homem de S. Tahla; vê nele um lugar que vai arrebatar. E atrás do Hotel des Bois, deitada no campo de centeio, vê o casal de amantes na moldura da janela, palco de luz que Tatiana, nua em seu cabeleria negra (p. 47), atravessa lentamente.

Nos dias seguintes, faz por onde passar por acaso na porta da casa de Tatiana. Ela a reconhece, Tatiana apresenta a Lol Pierre Beugner, seu marido, e Jacques Hold, um de seus amigos, a distância é percorrida, eu (p. 55) - o pronome que escapa à ordenação sintática da frase e se isola. Só esse instante dá a conhecer o nome do narrador, Jacques Hold, e Tatiana Karl se torna então a mulher dele em S. Tahla.

Tatiana retribui a visita. Tatiana faz perguntas, e Lol responde com frases inacabadas - as reticências aparecem na tradução da primeira dessas frases (p. $70)^{15}$ - que depois voltam a aparecer, quando a história se encaminha para o final. Esse inacabamento se repete cada vez mais. Essa palavra que não se diz e que só resta a M. Duras fazer ressoar, ausência de amor, permanece à espreita numa curva da linguagem, e desafia a tradução.

Lol se torna, afinal, a amante do Homem de S. Tahla, amante de Tatiana Karl. E Lol precisa dela para se fazer um corpo e manter a distância segura e necessária à entrega a que não se dispõe. Refaz afinal a tríade em que era a terceira com Michael Richardson e Anne-Marie Stretter. Jacques Hold é agora o arrebatado. A loucura se desencadeia, e ela pode deitar-se mais uma vez, frente à janela do Hotel des Bois, e dormir no campo de centeio.

Leixa é também o que resta no campo após a colheita.

É preciso, então, que se parta desse lugar entretempos, que se resista a submeter esse não-sabido que sabe - l'insu que sait, como diz Lacan - à ordem de um saber da língua que se oferece à compreensão, que se deixe guiar por uma escuta - como diz Nancy - disposta ao afeto. É preciso correr o risco de traduzir

15 - Você o escuta sempre? / - Quase sempre. Principalmente quando eu... A diferença é que as reticências, além de indicarem uma suspensão no fraseado, subtendem que o leitor seja capaz de completar o que seria dito; subtendem que o leitor saiba, e não há o que saber. Algumas frases inacabadas não estão marcadas por reticências. 
expondo as escansões, os esgarçamentos, os elementos desarmônicos, sem tentar estancar essa diferença que não se diz e que só se pode fazer ressoar.

A escrita de Marguerite insiste como criação. E para habitar esse escrito pondo-se em tradução sem nele se perder é preciso lutar com o duende de que fala Garcia Lorca, esse poder misterioso e inapreensível que rompe os estilos passíveis de um estabelecimento. É dessa palavra-buraco que não cessa de (não) se escrever e se traduzir que Marguerite tira com zelo suas letras, e anuncia, nas palavras do poeta andaluz, o constante batismo das coisas recém-criadas (1968, p. 121), toujours en allée.

É preciso haver, em alguma medida, um desejo de traduzir, de estar aberto ao que se mostra intangível na língua de Marguerite e também na língua de tradução; algo de que não podemos nos apropriar, e que se pode chamar - por que não? - de intraduzível. Reivindicar para ambos, para o original e para sua tradução, o direito à opacidade, de que fala o poeta Édouard Glissant: "Já não me é necessário compreender o outro, quer dizer, reduzi-lo ao modelo de minha própria transparência, para viver com esse outro e construir com ele. O direito à opacidade seria hoje o signo mais evidente da não-barbárie” (2005, p. 86). 
Veras, M. V. Marguerite Duras, Lol V. Stein: escrita e tradução em andamento

\section{Referências}

BENJAMIN, W. A tarefa do tradutor. Trad. Susana Kampff Lages. In: Heidermann, Werner (Org.). Clássicos da teoria da tradução (Antologia bilíngue alemão-português). v. 1, 2. ed. rev. e aum. Florianópolis: UFSC, 2010, p. 202-231.

BLANCHOT, M. O espaço literário. Trad. Álvaro Cabral. Rio de Janeiro: Rocco, 1987.

A conversa infinita: a palavra plural. Trad. Aurélio Guerra Neto. São Paulo: Escuta, 2010.

DURAS, M. Escrever. Trad. de Rubens Figueiredo. Rio de Janeiro: Rocco, 1994. Le ravissement de Lol V. Stein. Paris: Gallimard, 1964.

O deslumbramento. Trad. Ana Maria Falcão. Rio de Janeiro: Nova Fronteira, 1986.

DURAS, M.; GAUTHIER, X. Les parleuses. Paris: Les Éditions de Minuit, 1974.

DURAS, M.; PORTE, M. Les lieux de Marguerite Duras. Paris: Éditions de Minuit, 1977.

FREUD, Sigmund. O estranho (1919). In: Edição Standard Brasileira das Obras Completas de Sigmund Freud: História de uma neurose infantil e outros trabalhos. Coord. Trad. Jayme Salomão. V. 17. Rio de Janeiro: Imago, 1996.

O inquietante (1919). In: Obras Completas de Sigmund Freud - Volume 14. Tradução e notas de Paulo César de Souza. SP: Companhia das Letras, 2010.

GARCÍA LORCA, F. Teoría y Juego del Duende. In: Obras Completas. Recompilação e notas de Arturo Del Hoyo. 14ª ed. Madrid: Aguilar, 1968, p. 109-121.

GLISSANT, É. Introdução a uma poética da diversidade. Trad. Enilce Albergaria Rocha. Juiz de Fora: UFJF, 2005.

KUNDERA, M. L'art du roman. Paris: Gallimard, 1986.

LACAN, J. (1965) "Homenagem a Marguerite Duras pelo arrebatamento de Lol V. Stein". In: Shakespeare, Duras, Wedekind, Joyce. Trad. Eunice Martinho. Org. José Martinho. Lisboa: Assírio \& Alvim, 1989.

(1965) Homenagem a Marguerite Duras pelo arrebatamento de Lol V. Stein. In: Outros Escritos. Trad. Vera Ribeiro. Rio de Janeiro: Zahar, 2003.

Revista Letras,

Curitiba, UFPR,

n. 95 60-72,

jan./jun. 2017.

ISSN 2236-0999

(versão eletrônica) 
. (1965) "Hommage fait à Marguerite Duras, du ravissement de Lol V. Stein”. In: Autres écrits. Paris: Seuil, 2001.

(1973) "O aturdito". In: Outros Escritos. Trad. Vera Ribeiro.

Rio de Janeiro: Zahar, 2003.

NANCY, J-L. À l'écoute. Paris: Galilée, 2002.

NAVA, G. Lettres de Ferdinand de Saussure à Giovanni Pascoli. Cahiers

Ferdinand de Saussure, n. 24, p. 73-81, Genève, Droz, 1968.

SZAMOSI, G. The Origin of Time. How Medieval Musicians Invented the Forth Dimension. The Sciences, set-out., 1986, p. 33-39.

Submetido em: 05/11/2016

Aceito em: 22/12/2016 